Session 2559

\title{
Integration of Design and Selected Process Engineering Components into the Unit Operations Laboratory
}

\author{
Muthanna H. Al-Dahhan \\ Chemical Engineering Laboratory \\ Washington University \\ St. Louis, MO 63130
}

Introduction

ABET 2000 criteria require each educational program to include meaningful design experience that grows with the students' development ${ }^{1}$. Design of any chemical, petroleum, biochemical, materials, environmental, etc. process involves proper selection and sizing of various process engineering components such pipes, tubes, valves, regulators, filters, pumps, compressors, mixers, instruments, etc. Most of these components are integrated into the set-ups used in a unit operations laboratory. Often the students start the unit operations laboratory without prior experience with or technical knowledge of these components. As a result the students seldom appreciate the need for such knowledge and experience that leads to the proper design, sizing, selection and operation of these components. Since ABET emphasizes the outcomes that are based on practicing profession of engineering, we found it very useful to have one-hour lectures as a part of the laboratory course in which we discuss various process components, their specifications, principles of operation, range of applications, reliability, safety, economic factors, and the basis for their selection in meeting a desired need.

The covered material helps to enhance the knowledge of our students with respect to the design, proper selection, sizing and operation of these components. The course structure provides students with a head start regarding the technical knowledge they need in practicing engineering. Hence, this paper describes the integration of the technical knowledge of various process engineering components into the chemical engineering curricula through the unit operation laboratory to meet the need for engineering practice.

\section{Course Structure}

The structure that integrates the technical knowledge of various process engineering components into the unit operations laboratory is illustrated in Figure 1. The technical details of the listed process components are discussed during the above mentioned one-hour lecture session. Since the chemical engineering laboratory courses I and II (ChE 374 and ChE 473) are offered over two semesters, the lectures' contents are covered over these two semesters according to the schedule shown in Figure 1. The methodology used to select these process components is based on the author's industrial experience, the extent of their industrial applications, their presence as a part of our laboratory experimental set-ups, suggestions provided by process engineers from 
local industry, and based on complementing the topics taught in other chemical engineering courses.

To enhance the relevant experience-based learning process and to prepare our students for their future as professionals a comprehensive technical text-notebook (manual) ${ }^{2}$ has been developed to discuss these components. The manual consists of detailed technical information of the components, that includes specifications, principle of operation, basis for their selection, process safety and environmental issues as well as schematics and pictures. The contents of this notebook have been obtained from technical manuals published by the manufacturers, technical books for process design and technical information obtained from local industry., ${ }_{3,5,6,7,8,9,10,11} \mathrm{~A}$ brief description of the contents of the developed notebook is listed in Table 1.

Experts from local industry are usually invited to discuss some of these components with practical industrial examples that show how to implement the knowledge acquired into efficient process design and operation. The subjects that are covered by the industrial experts vary based on their availability. The interactions between the students and the industrial speakers provide a collaborative learning environment ${ }^{2}$ and are valuable to the students, both of which make the lectures a pleasurable experience.

In addition, at least one field trip is arranged each semester to local industry where the students are exposed to the role of the above described engineering components as essential parts of different industrial unit operations.

Homework assignments, case studies and exams are included in the covered materials. The industrial invited speakers participate in formulating the problems that are practically oriented towards proper design and selection of process components for different applications.

\section{Remarks}

The contents of this series of lectures along with the laboratory experiments provide useful technical and design knowledge needed for engineering practice. This is confirmed by the feedback received from our graduates. As an example of the outcome, Matt Corry, who graduated from our department in 1998 and is currently a process design engineer at Monsanto EnviroChem Systems, wrote "The need to be familiar with all the piping, valves, pumps, etc. along with the theoretical design concepts is required considering that a design engineer not only has to design the plant, but has to start up, troubleshoot, and operate the plant. The design engineer requires not only theoretical number crunching ability, but also practical experience and know-how as well. I believe that your lectures and labs have given me the important diverse education that is required for a typical chemical engineering career", The quantity and quality of information that is provided in the manuals and the labs are very helpful in the everyday use for a Process Engineer. I hope you can relate the message to your current students of how important and useful this information is to the typical chemical engineer". 
Bibliography

1. Details about EC2000 can be found at the ABET web site. <http://www.abet.org>

2. Al-Dahhan, M.H. Engineering Process Components. Chemical Engineering Department, Washington University, St. Louis, Missouri, (1999).

3. Brown, A. \& Palinscar, A. Guided Cooperative learning and individual knowledge acquisition. In L. Resnick (Ed.), Knowing, Learning, and Unstruction: Essays in Honor of Robert Claser. Hillsdale, NJ: Erlbaum (1989).

4. Ludwig, E. Applied Process Design. Volumes I,II \& III. Gulf Publishing Co., Houston, Texas, (1995).

5. Lieberman, N. Process Design for Reliable Operations. Gulf Publishing Co., Houston Texas, (1983).

6. Cheremisinoff, N. Process Level Instrumentation and Control. Marcel Dekker, Inc. New York, New York, (1981).

7. Kletz, T. What Went Wrong? Case Histories of Process Plant Disasters. Gulf Publishing Co., Houston Texas, (1994).

8. CCPS - Guidelines for Safe Automation of Chemical Processes. AIChE, New York, New York, (1993).

9. CCPS - Guidelines for Engineering Design for Process Safety. AIChE, New York, New York, (1993).

10. CCPS - Guidelines for Design Solutions for Process Equipment Failures. AIChE, New York, New York, (1998).

11. Underwood, A. Electrical Power Generation and Distribution, Class-note, Washington University, St. Louis, MO, (1990).

\section{MUTHANNA H. AL-DAHHAN}

Muthanna Al-Dahhan is Assistant Professor of Chemical Engineering and Associate Director of the Chemical Reaction Engineering Laboratory at Washington University in St. Louis. He received his Master's degree from Oregon State University (1988), and his Doctoral degree from Washington University (1993), all in chemical engineering. His research interests are in chemical reaction engineering, multiphase reactor systems, mass transfer and biochemical process engineering. 


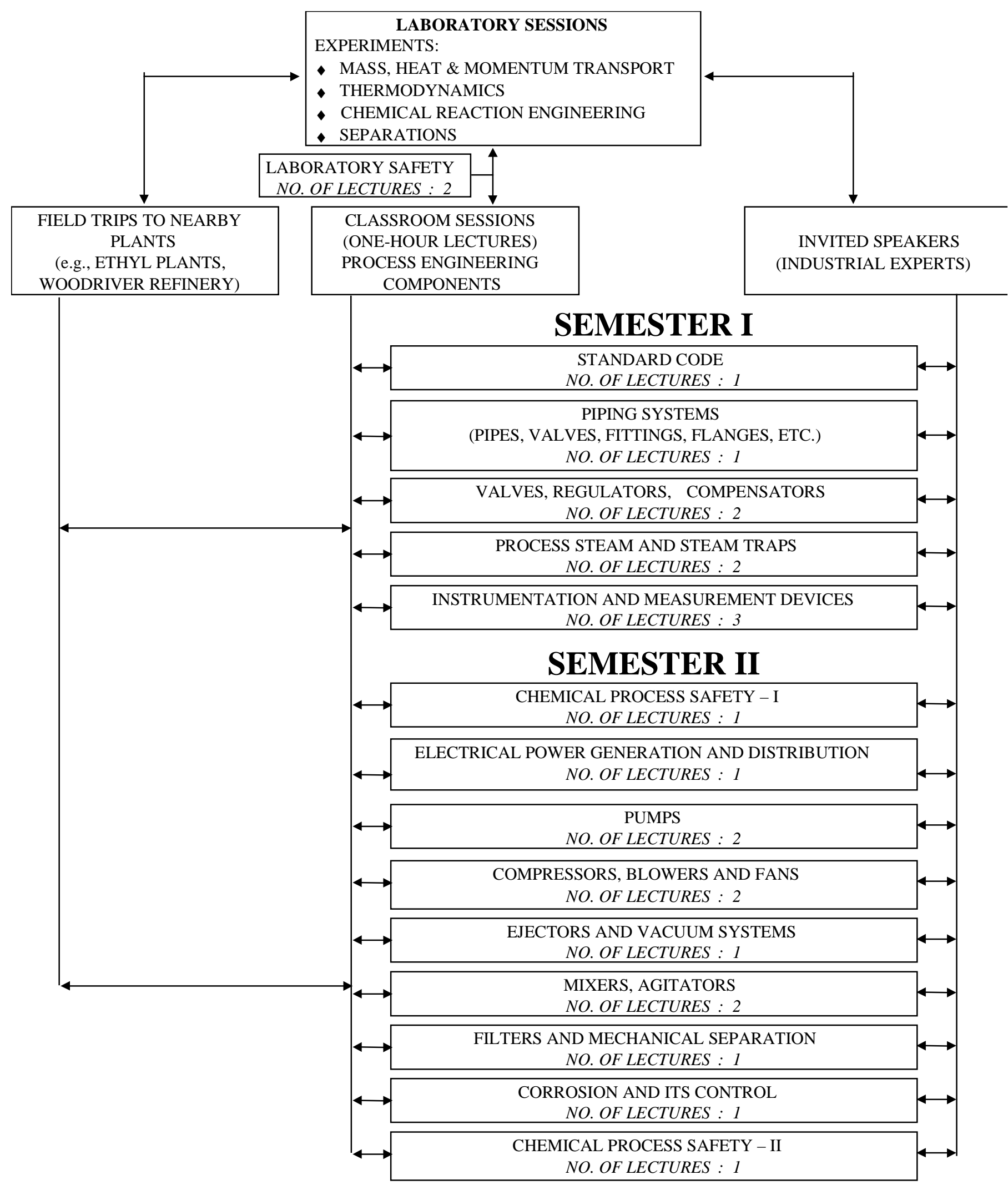

FIGURE 1: Schematic diagram of the integration of design and selected process engineering components into the unit operations laboratory 
TABLE 1: A brief description of the contents of the developed technical manual (notebook).

\begin{tabular}{|c|c|}
\hline SUBJECT & BRIEF DESCRIPTION \\
\hline Laboratory Safety & $\begin{array}{l}\text { Laboratory safety rules and procedures are discussed and } \\
\text { emphasized. }\end{array}$ \\
\hline Standard Codes & $\begin{array}{l}\text { Codes, standards, recommended practices and guides are defined and } \\
\text { discussed. Examples are presented that show how these standard } \\
\text { codes are used for design, materials selection, equipment fabrication, } \\
\text { installation and inspection to insure public and industrial safety in a } \\
\text { particular technical activity. Different types of codes organizations } \\
\text { are presented and their objectives and roles are highlighted. }\end{array}$ \\
\hline $\begin{array}{l}\text { Process Piping } \\
\text { Systems }\end{array}$ & $\begin{array}{l}\text { Piping and tubing systems and their components (e.g. valves, } \\
\text { flanges, fittings, etc.) provide the means for transporting material } \\
\text { between various pieces of processing equipment. In many cases, } \\
\text { they are an integral part of the equipment. Piping systems are often } \\
\text { the largest cost item of any process. They also represent the greatest } \\
\text { cause of losses. For example, about } 31 \% \text { of the accidents in } \\
\text { chemical and petroleum plants are caused due to failure in piping } \\
\text { systems }{ }^{1} \text {. Therefore, they must be designed, chosen and installed } \\
\text { properly according to the relevant codes. Different types of pipes } \\
\text { and tubes are discussed. Types of connections such as threaded and } \\
\text { welded connections, fittings and flanges are covered along with the } \\
\text { basis for their selection and applications. The laboratory technician } \\
\text { arranges for the class a workshop on piping and fitting. Cross } \\
\text { sections of different piping and tubing connectors are mounted on a } \\
\text { board in the laboratory for demonstration. }\end{array}$ \\
\hline $\begin{array}{l}\text { Valves, Regulators } \\
\text { and Compensators }\end{array}$ & $\begin{array}{l}\text { Proper valve selection is essential for a well-designed piping system. } \\
\text { Different types of valves are discussed such as gate, globe, angle, } \\
\text { ball, diaphragm, butterfly, needle, metering and check valves. Each } \\
\text { valve type has its specific use. Therefore, emphasis is given to their } \\
\text { application and selection. } \\
\text { Regulators: Different regulator valves are discussed, such as } \\
\text { mechanically/electrically actuated valves (air to open and air to } \\
\text { close), relief valves and pressure and back pressure regulator valves. } \\
\text { Specific attention is given to their selection in the light of process } \\
\text { safety and environmental issues. A demonstration unit of a } \\
\text { mechanically actuated valve was developed in the lab where the } \\
\text { students are asked to operate it and understand its operating } \\
\text { principle. }\end{array}$ \\
\hline
\end{tabular}




\begin{tabular}{|c|c|}
\hline & $\begin{array}{l}\text { Compensators: During operation different parts of process equipment } \\
\text { reach different temperature, which results in additional thermal } \\
\text { stresses to rigid structures. The rigid structure is not applicable if the } \\
\text { total stresses (from both the pressure of the processing fluid and } \\
\text { thermal stresses) become greater than the permitted limits. } \\
\text { Therefore, compensators should be provided for apparati operating } \\
\text { under such conditions. Different types of compensators are } \\
\text { discussed. } \\
\text { Samples of these components are demonstrated in the classroom and } \\
\text { cross sections of different types of these components are available in } \\
\text { the laboratory on the demonstration board. }\end{array}$ \\
\hline $\begin{array}{l}\text { Process Steam and } \\
\text { Steam Trap }\end{array}$ & $\begin{array}{l}\text { Different ways of generating steam that are commonly used in } \\
\text { industry are discussed. Steam provides heat to the process } \\
\text { equipment by condensation (removing the latent heat) and hence the } \\
\text { condensate must be removed as fast as it forms in order for the } \\
\text { heating process to continue efficiently. This can be achieved by } \\
\text { steam traps, which do not allow the uncondensed steam to escape the } \\
\text { heat exchanging equipment because this would be wasteful and } \\
\text { increase the cost. There are different types of steam traps available. } \\
\text { In the lecture these are discussed and practical outline of the basis } \\
\text { and the importance of a proper selection of the steam traps are } \\
\text { provided. Cross sections of different types of steam traps are } \\
\text { presented to the students in the laboratory on the demonstration } \\
\text { board. }\end{array}$ \\
\hline $\begin{array}{l}\text { Instrumentation and } \\
\text { Measurements in } \\
\text { Industry }\end{array}$ & $\begin{array}{l}\text { Industrial processes range from simple processes to exceedingly } \\
\text { complex operations. Instrumentation and measurements are one of } \\
\text { the most important parts of the processes. Accurate measurements } \\
\text { and control provide safe operations and give uniform and higher } \\
\text { quality products leading to higher profits. In these lectures the } \\
\text { principles, types and the basis of selection of various instrumentation } \\
\text { and measurement devices for flow of liquid and gases, temperature, } \\
\text { pressure, liquid level are discussed. }\end{array}$ \\
\hline $\begin{array}{l}\text { Chemical Process } \\
\text { Safety I }\end{array}$ & $\begin{array}{l}\text { This lecture is given at the beginning of the second semester of the } \\
\text { chemical engineering laboratory after the students have practiced } \\
\text { some safety rules in the laboratory and worked with different } \\
\text { equipment and components discussed above. The lecture is focused } \\
\text { on the following: OSHA and its role, OSHA regulatory processes, an } \\
\text { overview of the areas of consideration for an in-process safety } \\
\text { review and requirement, process safety management, rules, hazard } \\
\text { identification and risk assessment and the role of process safety } \\
\text { consideration in process design. }\end{array}$ \\
\hline
\end{tabular}




\begin{tabular}{|c|c|}
\hline $\begin{array}{l}\text { Electrical Power } \\
\text { Generation and } \\
\text { Distribution }\end{array}$ & $\begin{array}{l}\text { Mechanical energy is needed throughout the chemical plant to drive } \\
\text { pumps, blowers, crushers, screens, centrifuges, agitators, conveyers, } \\
\text { and so on. The most convenient and economical source of this } \\
\text { energy is usually an electric motor. Electrical energy is clean, cheap } \\
\text { and quiet, and it arrives on demand. Its conversion to mechanical } \\
\text { energy is simple, reliable and easily controlled. Without electrical } \\
\text { energy, the plant could not operate. It, therefore, behooves the } \\
\text { chemical engineer to have at least a preliminary understanding of } \\
\text { electric motors, principle of power generators and power distribution } \\
\text { systems. }{ }^{11} \text {. Accordingly, the prepared materials enhance the } \\
\text { knowledge and the hands-on experience obtained in the laboratory } \\
\text { during execution of the experiment related to the characterization of } \\
\text { the pump and motor performance. }\end{array}$ \\
\hline $\begin{array}{l}\text { Pumping of Liquids: } \\
\text { Pumps }\end{array}$ & $\begin{array}{l}\text { Pumps are essential components for any process. There is a wide } \\
\text { variety of pumps. The general classification of pumps includes: } \\
\text { centrifugal (centrifugal, propeller, mixed flow, peripheral, turbine), } \\
\text { rotary (cam, screw, gear, vane, lobe) and reciprocating (piston, } \\
\text { plunger, diaphragm). These types and their components are } \\
\text { discussed with the emphasis on centrifugal pumps. The applications } \\
\text { and limitations of pump types and the basis for their selection are } \\
\text { covered. Typical centrifugal pump performance curves are illustrated } \\
\text { and its important parameters are highlighted. This subject enhances } \\
\text { the knowledge and the hands-on experience obtained in the } \\
\text { centrifugal pump experiment performed in the labs as a part of } \\
\text { characterizing the pressure drop in a piping system. A demonstration } \\
\text { unit of a cross-sectional centrifugal pump and its parts are } \\
\text { demonstrated in the laboratory. The industrial speaker provides a } \\
\text { workshop on utilizing software distributed by the manufacturer for } \\
\text { pump selection and sizing. }\end{array}$ \\
\hline $\begin{array}{l}\text { Pumping of Gases: } \\
\text { Compressors, Blowers } \\
\text { and Fans }\end{array}$ & $\begin{array}{l}\text { Compression of gases and vapors is an important operation in } \\
\text { various processes. It is important to properly select the type of } \\
\text { equipment by its performance characteristics. There are many } \\
\text { different types of compressors such as reciprocating, centrifugal, } \\
\text { rotary, displacement and axial flow compressors. These types are } \\
\text { discussed along with their applications, limitations and the basis for } \\
\text { their selection. Performance considerations are covered which are } \\
\text { related to the thermodynamic concepts that the students covered in } \\
\text { their thermodynamics course. The compressor performance curves } \\
\text { are explained. } \\
\text { Discussions on blowers, vacuum pumps and fans are included. The } \\
\text { differences and applications of these equipment items are } \\
\text { highlighted. }\end{array}$ \\
\hline
\end{tabular}




\begin{tabular}{|c|c|}
\hline $\begin{array}{l}\text { Ejectors and Vacuum } \\
\text { Systems }\end{array}$ & $\begin{array}{l}\text { To create a vacuum in a system, it is required to draw out or pump } \\
\text { out the air in the system. There are many different types of } \\
\text { equipment and configuration used to create vacuum in a system. } \\
\text { These are reviewed and discussed. In addition, the vacuum safety } \\
\text { considerations are stressed. The evaporator set-up in our lab is } \\
\text { equipped with an ejector to create the needed vacuum by using steam } \\
\text { and water. The students are asked to discuss this configuration and } \\
\text { propose with explanation a better solution. }\end{array}$ \\
\hline $\begin{array}{l}\text { Agitation and Mixing } \\
\text { of Liquids }\end{array}$ & $\begin{array}{l}\text { Agitation refers to the induced motion of a material in a specified } \\
\text { way, while mixing is the random distribution, into and through one } \\
\text { another, of two or more initially separated fluids. These processes } \\
\text { are very important in industry since many processing operations } \\
\text { depend for their success on the effective agitation and mixing of } \\
\text { fluids. As part of this topic we cover the agitation and mixing } \\
\text { equipment. Their specification and design and selection } \\
\text { considerations are highlighted. The impeller types and the generated } \\
\text { flow patterns are discussed. A video tape that shows the mixing } \\
\text { obtained in a stirred tank using advanced diagnostic techniques such } \\
\text { as Laser Doppler Anemometry, radioactive particle tracking, particle } \\
\text { image velocimetry and visualization, are presented to the class. In } \\
\text { addition, a discussion of static mixers and their types, configurations } \\
\text { and applications is included. }\end{array}$ \\
\hline $\begin{array}{l}\text { Mechanical } \\
\text { Separation/Filtration }\end{array}$ & $\begin{array}{l}\text { Mechanical separation and filtration are used extensively in various } \\
\text { processes to separate liquid particles from vapor or gas, liquid } \\
\text { particles from immiscible liquid, dust or solid particles from vapor or } \\
\text { gas, solid particles from liquid and solid particles from other solids } \\
\text { particles. Different types of equipment are used for such separations. } \\
\text { The various types, their specifications, limitations and } \\
\text { design/selection considerations are discussed. Filtration processes } \\
\text { and filtration equipment are covered in more detail. Students are } \\
\text { asked to identify the filters used in the lab equipment, their } \\
\text { specifications and the basis for their selections. A process flow sheet } \\
\text { is given where the students are asked to include filters at needed } \\
\text { locations and select the proper types while providing the } \\
\text { rationalization for their selections. }\end{array}$ \\
\hline $\begin{array}{l}\text { Corrosion and } \\
\text { Corrosion Control }\end{array}$ & $\begin{array}{l}\text { Understanding corrosion and how to control it are very important } \\
\text { subjects that engineers should consider in design, operation and } \\
\text { maintenance. In this lecture different kinds of corrosion are } \\
\text { discussed. The principle of corrosion and the corrosion types are } \\
\text { covered. Attention is given to the factors that influence corrosion. } \\
\text { The measures that should be taken to control various types of } \\
\text { corrosion are outlined and stressed. Moreover, the factors that }\end{array}$ \\
\hline
\end{tabular}




\begin{tabular}{|l|l|}
\hline Chemical Process & $\begin{array}{l}\text { should be considered in the materials selection for equipment and } \\
\text { process design are discussed. }\end{array}$ \\
\hline Aafety II & $\begin{array}{l}\text { At the end of the semester and after the students have gained the } \\
\text { technical knowledge about the above mentioned process engineering } \\
\text { components, a lecture on implementation of process safety } \\
\text { considerations for safe and efficient process and equipment design is } \\
\text { delivered by an expert from industry. This lecture includes a } \\
\text { discussion of the types of relief devices and guidelines for their } \\
\text { sizing and positions. A workshop is organized for the class where } \\
\text { the speaker divides the students into groups to work on analyzing } \\
\text { practical problems. One of these problems is to complete a process } \\
\text { flow diagram with all the required process components, } \\
\text { instrumentation and control loops that ensure safe operation. The } \\
\text { other problem is an industrial safety problem which occurred in a } \\
\text { urea plant that caused a considerable damage to the unit. In this } \\
\text { exercise a description of the urea process, its components and } \\
\text { flowsheet, operating conditions and safety audit are given to the } \\
\text { groups. They are asked to discuss the case as a team to identify the } \\
\text { components and the design that caused the problem and how to } \\
\text { overcome it in a better process design. These case studies are } \\
\text { discussed in class in a collaborative learning environment } 2 \text { which } \\
\text { provides the students with invaluable experience and knowledge. }\end{array}$ \\
\hline
\end{tabular}

